\title{
Overturning Axis Selection in Curved Box-Girder Bridges with Single-Column Piers
}

\author{
Guohua Song $\mathbb{D}^{1},{ }^{1}$ Delu Che, ${ }^{2}$ and Minghui $\mathrm{Li}^{3}$ \\ ${ }^{1}$ School of Civil Engineering, Zhengzhou University, Zhengzhou, China \\ ${ }^{2}$ Henan Provincial Communications Planning and Design Institute Co., Ltd, Zhengzhou, China \\ ${ }^{3}$ The First Construction Co., Ltd of China Construction First Group, Shanghai, China
}

Correspondence should be addressed to Guohua Song; guohuasong_309@163.com

Received 19 October 2017; Revised 6 April 2018; Accepted 12 April 2018; Published 15 May 2018

Academic Editor: Roman Wendner

Copyright (C) 2018 Guohua Song et al. This is an open access article distributed under the Creative Commons Attribution License, which permits unrestricted use, distribution, and reproduction in any medium, provided the original work is properly cited.

\begin{abstract}
This study was conducted to theoretically analyze the overturning axes of curved box-girder bridges with three equal spans and single-column piers per the influence of curvature radius and bearing eccentricity on overturning axis. The theoretical analysis is verified by a model bridge experiment. The results show that overturning axis can be effectively determined according to the connecting line of either bearings at the central piers or outmost bearings at abutments as influenced by curvature radius and bearing eccentricity. In other words, no bearings are outside of overturning axis. All the bearings but the two on the overturning axis are located on the inner side of the axis. For curved bridges with multispans and single-column or double-column piers, the overturning axis is characterized by the connecting line of the two adjacent outmost bearings.
\end{abstract}

\section{Introduction}

Expanding transportation systems across China have resulted in an impressive number of newly constructed bridges. New bridges have eased traffic to some extent in urban areas but have also created serious problems. In developing countries, overloading is the primary reason inducing safety problems, particularly relating to trucks [1-6]. The overturning collapse of single-column-pier bridges is usually associated with overloading $[4,7]$ or occurs under an unexpected excess of eccentric load [8-11].

Bridges with single-column piers have simple substructure, are easy to construct, and show effective transparency of the horizon, making them popular in many overpass bridges and viaducts across the globe. However, bridges with singlecolumn piers are prone to overturning accidents due to their simple boundary conditions [8]. These accidents are typically caused by vehicles deviating from their normal lanes [12]. On a small or light curved ramp bridge, overturning moment resistance may suddenly fail to balance out the overturning moment caused by industrial trucks, especially in dense traffic or under heavy loads. When bearings separate, the boundary conditions of the superstructure fail and the girders are likely to overturn $[9,13]$.

Recently, several researchers have investigated overturning resistance of bridges [10-16]. Most studies center around whether newly built bridges have sufficient overturning resistance, whether single-column piers are safe enough to include in new bridge designs, and whether bridges without singlecolumn piers have better overturning resistance than those that do have them. Methods for checking the stability against overturning are rarely explicitly stated either in Chinese [17] or foreign $[18,19]$ studies. In China, the current code JTG D60-2015 [20] has neither specific regulations nor guiding methodology for this purpose. This lack of information leaves curved bridges susceptible to poor overturning resistance at the design stage and to overturning accidents at the service stage. There is urgent demand for new techniques for assessing stability against overturning in curved bridges [16, 21].

There is no consensus regarding the overturning mechanism of bridges. Researchers tend to adopt the factor of stability against overturning (FSO) to investigate stability against overturning in practice $[9,12]$, while overturning axis selection is rarely discussed. Jiang and Yang [22] determined an 


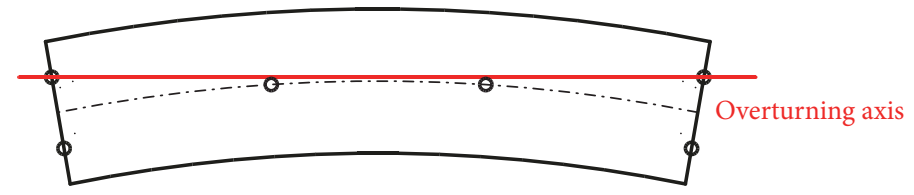

(a) Pier bearings lie inside the connecting line of outmost abutment bearings

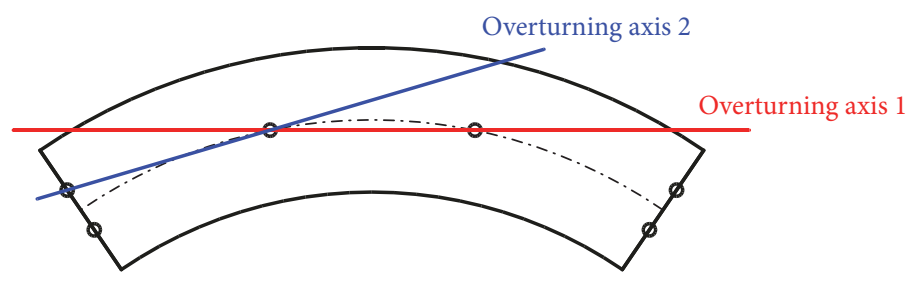

(b) Pier bearings lie outside the connecting line of outmost abutment bearings

FIgURe 1: Possible overturning axes.

overturning axis by the order of bearing separation; Zhou et al. [15] discussed selection of overturning axis of curved bridges under different bearing styles and different curvature radii; Yuan et al. [23] found that FSO differs with different overturning axes.

Curved bridges with single-column piers may have more than one overturning axis; the most dangerous axis should be identified in assessing the safety of the bridge. Overturning axis selection is influenced by many factors including curvature radius, bearing layout, and bridge width [15, 22, 24]. Overturning axis selection is effectively the very premise upon which overturning resistance analysis is conducted, which was the focus of the present study on curved bridges with single-column piers.

\section{Overturning Axis Selection Principle}

When a bridge overturns under a given load, the bearings begin to separate individually. Once they have all separated, the superstructure may reverse to overturn around a line connecting two bearings-this line is called the overturning axis. In an exposure draft of Chinese regulation (JTG D622012) [25], the overturning resistance of curved box-girder bridges is computed in three steps.

(1) First, the overturning axis location is determined according to the layout of the bridge bearings. As mentioned above, the overturning axis is the line connecting the last two effective bearings after a sequence of bearing failures under vehicle load, where the bridge can reverse around the axis.

(2) The balancing and unbalancing effects of various actions are worked out under various loads based on the overturning axis.

(3) The FSO is determined by the ratio of balancing effects to unbalancing effects. Only once the overturning axis is located can the overturning moment, antioverturning moment, and FSO be accurately defined.

The overturning axis selection principle in the exposure draft (JTG D62-2012) [25] is illustrated in Figure 1. If all the pier bearings lie inside the connecting line of outmost abutment bearings from the circle center, the connecting line is the overturning axis (Figure 1(a)). If all the pier bearings lie outside of the connecting line of outmost abutment bearings, the overturning axis can be either the connecting line of two adjacent pier bearings (overturning axis 1 in Figure 1(b)) or the connecting line of the outmost abutment bearing and its adjacent pier bearing (overturning axis 2 in Figure 1(b)).

If the curvature radius of the curved bridge is large, the overturning axis can be selected as shown in Figure 1(a); if the curvature radius is small, the overturning axis can be determined from two selections as shown in Figure 1(b) by comparing the two axes. In practice, it is necessary to make such selections per the "worst-case" scenario. Thus, the selection principle for overturning axes has two parts:

(1) All the bearings lie on one side of the axis but there are two on the overturning axis;

(2) The overturning axis is in the worst possible position, that is, the FSO is minimal.

The first clause of the selection principle agrees with the overturning axis selection method in the exposure draft (JTG D62-2012) [25]. For curved bridges with small curvature radii, however, there would be two axes to choose from (meriting the second clause).

A series of finite element models were made with a portion of an overpass ramp as a prototype to investigate the selection method, calculate FSO, and determine the effects of curvature radius and bearing eccentricity. According to Chinese code JTG D62-2012 (the exposure draft) [25], the FSO for a curved box-girder bridge is expressed as follows:

$$
k_{q f}=\frac{S_{b k}}{S_{s k}}=\frac{\sum F_{G i} x_{i}}{(1+\mu)\left(q_{k} \Omega+P_{k}\right) d},
$$

where $k_{q f}$ is the FSO; $S_{b k}$ is the combination of characteristic action effects which stabilizes the superstructure; $S_{s k}$ is the characteristic action of traffic load (including impact action) which overturns the superstructure; $q_{k}$ is the uniform load in lane loads; $P_{k}$ is the concentrated load in lane loads; $F_{G i}$ is 


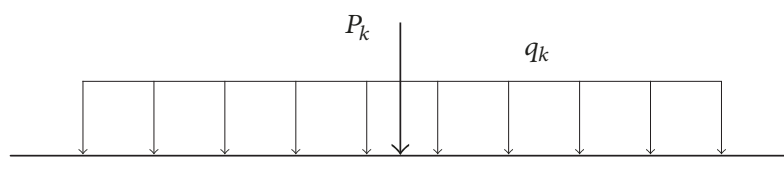

FIGURE 2: Lane load pattern.

TABLE 1: Standard values of $P_{k}$ for Highway Grade I.

\begin{tabular}{lccc}
\hline Concentrated load & \multicolumn{3}{c}{ Calculated span $l(\mathrm{~m})$} \\
& $l \leq 5$ & $5<l<50$ & $l \geq 50$ \\
\hline$P_{k}(\mathrm{kN})$ & 270 & $2(l+130)$ & 360 \\
\hline
\end{tabular}

every bearing reaction of the finished bridge under dead load; $\mu$ is the impact factor of traffic load; $x_{i}$ is the perpendicular distance from each bearing to the overturning axis; $\Omega$ is the area enclosed by the overturning axis and lateral loading lane; $d$ is the maximum perpendicular distance from the lateral loading lane to the overturning axis.

There are two types of loading models for imposed traffic load: one is lane load and the other is vehicle load. Lane load is for the overall bridge, and vehicle load is for local loading of bridge, soil pressure of culvert, abutment, and revetment. The above two loading models cannot be superposed because of different corresponding calculation pattern.

According to Chinese regulation [20], two different grades of standard values of traffic load, Highway Grade I and Highway Grade II, are applied for different road design. Lane load is composed of uniform load and concentrated load shown in Figure 2.

(1) For Highway Grade I, the standard value of uniform load $q_{k}=10.5 \mathrm{kN} / \mathrm{m}$ and concentrated load $P_{k}$ is taken as in Table 1. When calculating shear effect, the values of $P_{k}$ will be multiplied by 1.2 .

(2) For Highway Grade I, the standard values of $q_{k}$ and $P_{k}$ are 0.75 times those of Highway Grade I.

\section{Model Setup}

3.1. Project Profile. In order to compute the FSO of curved box-birder bridges and investigate the influencing parameters, the finite element models with different curvature radius were made to determine the overturning axes. In this paper, models were made with a part of overpass ramp as prototype. The structures were concrete box-girder bridges with threespan length of $3 \times 25 \mathrm{~m}$ and with single-cell single-box sections. The central piers were single-column piers; double torsional bearings were set at the two abutments with the bearing central space of $2.6 \mathrm{~m}$. The traffic load was Highway Grade I.

\subsection{Model Making}

Section Size. The height of girder was $1.8 \mathrm{~m}$, the width of top slab was $8.8 \mathrm{~m}$, the width of bottom slab was $4.1 \mathrm{~m}$, the thickness of cantilever end was $0.2 \mathrm{~m}$, and the root of cantilever was circularly connected. The section profile was shown in Figure 3.

Material Characteristics. In superstructure the concrete grade C50 was applied, in which modulus of elasticity $E=3.45 \times$ $10^{7} \mathrm{kN} / \mathrm{m}^{2}$, Poisson ratio $\mu_{p}=0.2$, and density $\rho=25 \mathrm{kN} / \mathrm{m}^{3}$.

Secondary Dead Loads. Concrete C40 was laid on bridge deck with thickness of $0.08 \mathrm{~m}$, pitch was $0.09 \mathrm{~m}$ thick, and between them was waterproof layer. Crash barriers were set at two sides of bridge with concrete $\mathrm{C} 30$, and the barriers were $0.5 \mathrm{~m}$ wide at the bottom.

Boundary Conditions. Bearings were fixed in radial direction and vertical directions and were movable in bridge axial direction. One central pier was fixed, and the abutments were torsion resistant.

The Superstructure. The superstructure was modeled with beam unit. For computational accuracy, the whole bridge was divided into 75 units uniformly, or one unit per meter. A finite element model of superstructure was shown in Figure 4.

Live Loads. In order to study the integrated stability against overturning of bridge, according to JTG D60-2015 [20], the lane load of Highway Grade I was acted; the loading location was $1.4 \mathrm{~m}$ from lane axis to crash barrier and was $0.5 \mathrm{~m}$ from outmost vehicle wheel to crash barrier which was shown in Figure 4 .

Parameters of Models. There were two parameters, curvature radius $R$ and bearing eccentricity $e$, which are shown in Figure 5, and whose influences were studied on FSO. The values of $R$ were 50,100, 200, 300, 400, 500, 600, 700, 800, 900 , and $1000 \mathrm{~m}$. The values of $e$ outward of central pier were $0,0.1,0.2,0.3,0.4$, and $0.5 \mathrm{~m}$. Altogether there were 6 $\times 11=66$ models made according to value ranges of parameters.

\section{Influence of Curvature Radius and Bearing Eccentricity on Overturning Axis Selection}

In practice, if comparison among FSOs is conducted under different curvature radii and bearing eccentricities, the workload would double. According to the first clause of the selection principle, the possible amount of overturning axes in models with different curvature radii and bearing eccentricities is shown in Figure 6.

Figure 6 shows that more than half of the possible models have two overturning axes. Models with curvature radius below $400 \mathrm{~m}$ have two overturning axes: one is the connecting line of two central bearings and the other is the connecting line of outmost bearings at the abutment with adjacent central bearings. Models with curvature radius above $800 \mathrm{~m}$ have one overturning axis: the connecting line of the two central bearings. Models with curvature radius between $500 \mathrm{~m}$ and $700 \mathrm{~m}$ have an overturning axis that is influenced by bearing eccentricity, because the central bearing is almost in line with the outmost bearing of the abutment. In this case, an increase 


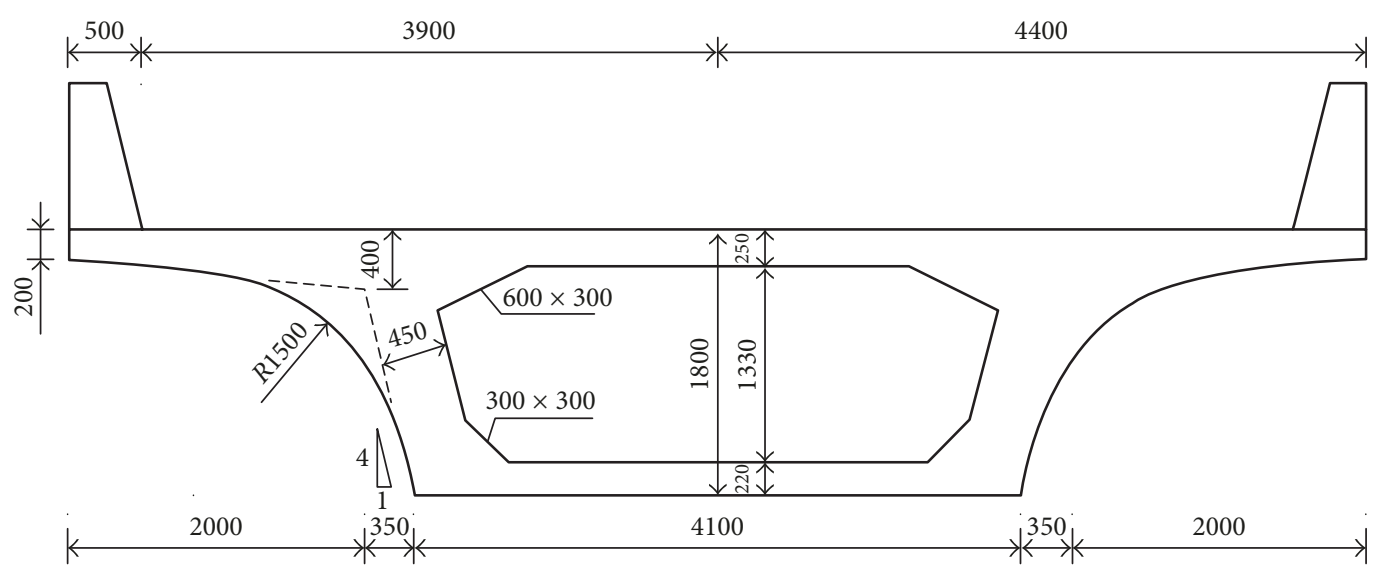

FIGURE 3: Section dimensions (mm).

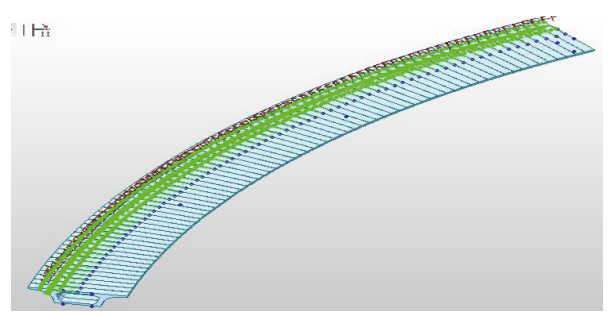

FIGURE 4: Finite element model of superstructure and lane loading.

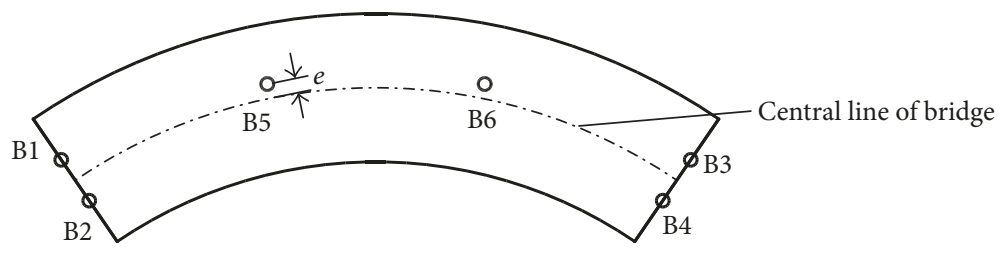

FIGURE 5: Bearing layout and numbering of a curved bridge.

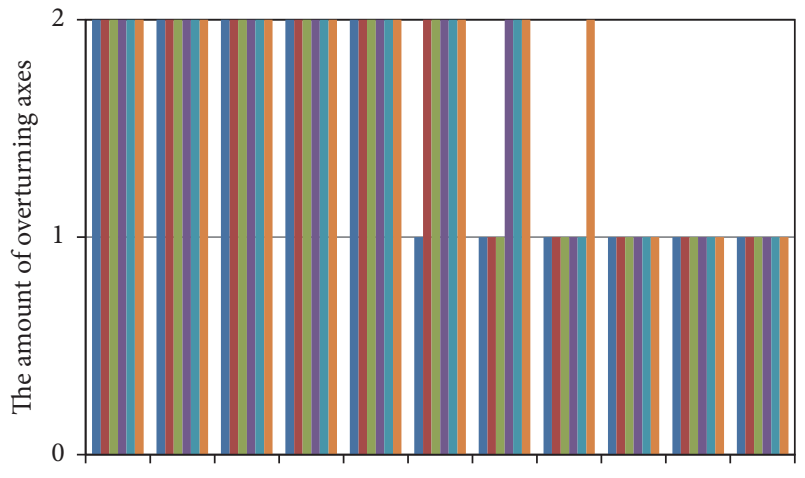

$\begin{array}{lllllllllll}50 & 100 & 200 & 300 & 400 & 500 & 600 & 700 & 800 & 900 & 1000\end{array}$ Curvature Radius $R(\mathrm{~m})$

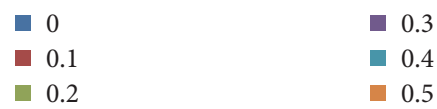

FIGURE 6: Quantity of overturning axes in model bridges.

in central bearing eccentricity is more likely to change the selection mode from a single overturning axis to double overturning axes in the overall bearing layout (Figure 1). Again, for curved bridges with two possible overturning axes, the second clause of the selection principle is necessary.

\section{Selection of Overturning Axis}

5.1. Overturning Axis Selection Analysis. According to (1), in calculating the FSO of curved bridges with two overturning axes, the values of $F_{G i}, \mu, q_{k}$, and $P_{k}$ are determinate, but the values of $\Omega, x_{i}$ and $d$ are indeterminate. The FSO values were compared in Axis 1 and in Axis 2 as shown in Figure 7.

Analysis was conducted under the following guidelines shown in Figure $7(a)$. First, the connecting line of $B_{5}-B_{6}$ was extended to intersect the circle on which the outmost contour line of the bridge is located at two points $\mathrm{A}$ and $\mathrm{B}$. Second, the connecting line $B_{1}-B_{5}$ was extended to intersect the outer circle at points $\mathrm{C}$ and $\mathrm{D}$. Third, the central point of line $\overline{\mathrm{AB}}$ is point $\mathrm{N}$, so point $\mathrm{N}$ and circle center $\mathrm{O}$ were connected and then a circle was plotted through $\mathrm{N}$ with point $\mathrm{O}$ as the circle center. Forth, tangent line $\overline{\mathrm{B}_{5} \mathrm{M}}$ was plotted through point $B_{5}$ making $M$ the tangency point and then the 


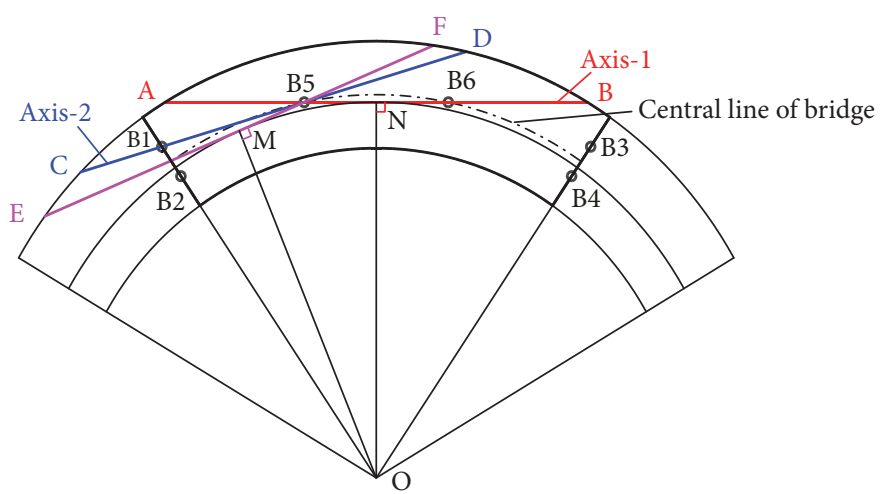

(a) Schematic diagram of overturning axis selection

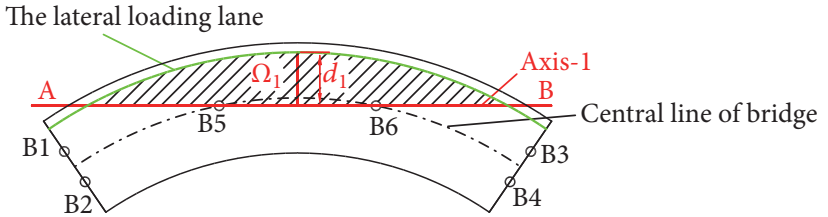

(b) Parameters $\Omega$ and $d$ for overturning axis 1

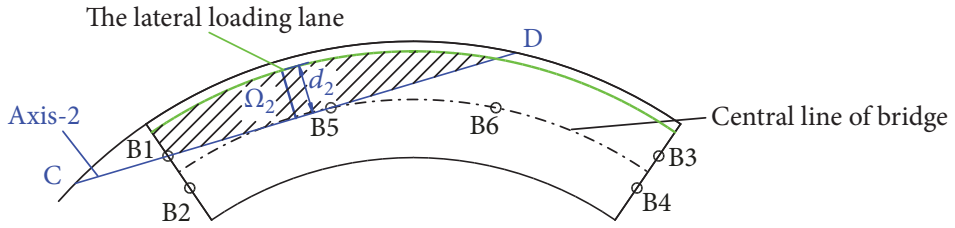

(c) Parameters $\Omega$ and $d$ for overturning axis 2

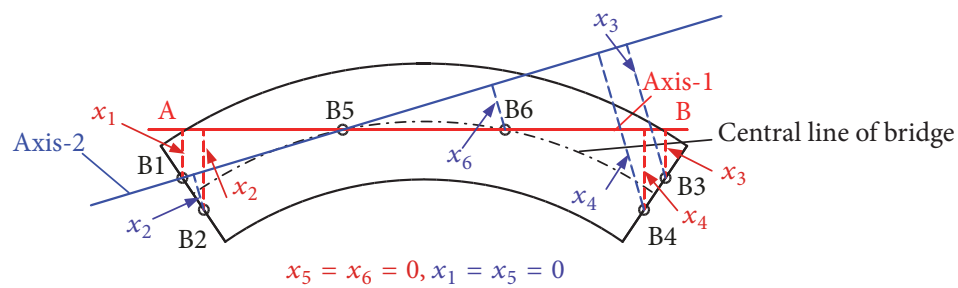

(d) Distances $x_{i}$ for axis 1 and axis 2 (the red is for axis 1 , and the blue is for axis 2)

FIGURE 7: Overturning axis selection analysis.

line $\overline{\mathrm{B}_{5} \mathrm{M}}$ was extended to intersect the outer circle at points $\mathrm{E}$ and $\mathrm{F}$.

Points $\mathrm{M}$ and $\mathrm{N}$ are on the same circle, so $\overline{\mathrm{OM}}=\overline{\mathrm{ON}}$ and both $\overline{\mathrm{AB}}$ and $\overline{\mathrm{EF}}$ are the secant lines through point $\mathrm{B}_{5}$; thus $\overline{\mathrm{AB}}=\overline{\mathrm{EF}} \cdot \overline{\mathrm{CD}}$ is out of arc $\widehat{\mathrm{MN}}$ which centers $\mathrm{O}$, so $\overline{\mathrm{CD}}<\overline{\mathrm{AB}}$. Thus, $S_{\widehat{\mathrm{CFD}}}<S_{\widehat{\mathrm{AFB}}}$; that is, $\Omega_{2}<\Omega_{1}$ and $d_{2}<d_{1}$ (Figures 7(b) and $7(\mathrm{c}))$; and $(1+\mu)\left(q_{k} \Omega_{2}+P_{k}\right) d_{2}<(1+\mu)\left(q_{k} \Omega_{1}+P_{k}\right) d_{1}$. In (1), the denominator of Axis 2 is less than that of Axis 1.

On the other hand, because $\overline{\mathrm{CD}}<\overline{\mathrm{AB}}, \overline{\mathrm{AB}}$ is nearer to circle center $\mathrm{O}$ than $\overline{\mathrm{CD}}$ and $\overline{\mathrm{AB}}$ is nearer to the centroid of all the bearings, including $B_{1}$ through $B_{6}$. Thus, in (1), the numerator $\sum F_{G i} x_{1 i}$ of Axis 1 is less than $\sum F_{G i} x_{2 i}$ of Axis 2 (Figure 7(d)).

Since the denominator of Axis 2 is less than that of Axis 1 , and the numerator of Axis 1 is less than that of Axis 2, $k_{q f 1}$ of Axis 1 is less than $k_{q f 2}$ of Axis 2, and Axis 1 is the target (i.e., selected) overturning axis.

\subsection{Verification of Overturning Axis Selection Analysis}

5.2.1. Verification by Models with Curvature Radius of $400 \mathrm{~m}$. The model with curvature radius of $400 \mathrm{~m}$ was used as an example to compute its FSO and determine its overturning axis, because it has two overturning axes to choose from under several possible bearing eccentricities.
TABle 2: Bearing reactions $F_{G i}$ of model bridges with $R=400 \mathrm{~m}$ $(\mathrm{kN})$.

\begin{tabular}{lcccccc}
\hline \multirow{2}{*}{ Bearing number } & \multicolumn{6}{c}{ Bearing eccentricity $e(\mathrm{~m})$} \\
& 0 & 0.1 & 0.2 & 0.3 & 0.4 & 0.5 \\
\hline $\mathrm{B}_{1}, \mathrm{~B}_{3}$ & 888 & 716 & 544 & 373 & 202 & 32 \\
$\mathrm{~B}_{2}, \mathrm{~B}_{4}$ & 760 & 935 & 1109 & 1283 & 1456 & 1630 \\
$\mathrm{~B}_{5}, \mathrm{~B}_{6}$ & 4523 & 4521 & 4518 & 4516 & 4513 & 4510 \\
\hline
\end{tabular}

According to Chinese regulation (JTG D60-2015) [20], the impact factor $\mu$ is determined by the structural fundamental frequency $f$, which is expressed in (2) as follows:

$$
\mu= \begin{cases}0.05 & f<1.5 \mathrm{~Hz} \\ 0.1767 \cdot \ln f-0.0157 & 1.5 \mathrm{~Hz} \leq f \leq 14 \mathrm{~Hz} \\ 0.45 & f>14 \mathrm{~Hz}\end{cases}
$$

In the calculations the structural fundamental frequency $f$ and impact factor $\mu$ were 4.81 and 0.26184 , respectively.

The bearing reactions $F_{G i}$ of models with curvature radius of $400 \mathrm{~m}$ in the finished bridge state are shown in Table 2.

Two axes were defined as shown in Figure 7(a), where Axis 1 is the connecting line of $\mathrm{B}_{5}$ and $\mathrm{B}_{6}$, while Axis 2 is 
TABLE 3: Distances $x_{i}$ from bearings to Axis 1 of model bridges with $R=400 \mathrm{~m}(\mathrm{~m})$.

\begin{tabular}{lcccccc}
\hline \multirow{2}{*}{ Bearing number } & \multicolumn{6}{c}{ Bearing eccentricity $e(\mathrm{~m})$} \\
& 0 & 0.1 & 0.2 & 0.3 & 0.4 & 0.5 \\
\hline $\mathrm{B}_{1}, \mathrm{~B}_{3}$ & 0.266 & 0.366 & 0.466 & 0.566 & 0.666 & 0.766 \\
$\mathrm{~B}_{2}, \mathrm{~B}_{4}$ & 2.855 & 2.955 & 3.055 & 3.155 & 3.255 & 3.354 \\
$\mathrm{~B}_{5}, \mathrm{~B}_{6}$ & 0 & 0 & 0 & 0 & 0 & 0 \\
\hline
\end{tabular}

TABLE 4: Distances $x_{i}$ from bearings to Axis 2 of model bridges with $R=400 \mathrm{~m}(\mathrm{~m})$.

\begin{tabular}{lcccccc}
\hline \multirow{2}{*}{ Bearing number } & \multicolumn{7}{c}{ Bearing eccentricity $e(\mathrm{~m})$} \\
& 0 & 0.1 & 0.2 & 0.3 & 0.4 & 0.5 \\
\hline $\mathrm{B}_{1}, \mathrm{~B}_{5}$ & 0 & 0 & 0 & 0 & 0 & 0 \\
$\mathrm{~B}_{2}$ & 2.591 & 2.592 & 2.593 & 2.593 & 2.594 & 2.595 \\
$\mathrm{~B}_{3}$ & 0.797 & 1.097 & 1.397 & 1.696 & 1.996 & 2.296 \\
$\mathrm{~B}_{4}$ & 3.383 & 3.682 & 3.980 & 4.279 & 4.577 & 4.876 \\
$\mathrm{~B}_{6}$ & 0.265 & 0.365 & 0.465 & 0.565 & 0.665 & 0.765 \\
\hline
\end{tabular}

TABLE 5: Areas $\Omega$ of model bridges with $R=400 \mathrm{~m}\left(\mathrm{~m}^{2}\right)$.

\begin{tabular}{lcccccc}
\hline \multirow{2}{*}{ Axis number } & \multicolumn{6}{c}{ Bearing eccentricity $e(\mathrm{~m})$} \\
& 0 & 0.1 & 0.2 & 0.3 & 0.4 & 0.5 \\
\hline Axis 1 & 158.6 & 151.1 & 143.6 & 136.1 & 128.6 & 121.1 \\
Axis 2 & 148.7 & 137.4 & 126.3 & 115.9 & 106.3 & 97.4 \\
\hline
\end{tabular}

TABLE 6: The maximum perpendicular distances $d$ of model bridges with $R=400 \mathrm{~m}(\mathrm{~m})$.

\begin{tabular}{lcccccc}
\hline \multirow{2}{*}{ Axis number } & \multicolumn{6}{c}{ Bearing eccentricity $e(\mathrm{~m})$} \\
& 0 & 0.1 & 0.2 & 0.3 & 0.4 & 0.5 \\
\hline Axis 1 & 2.695 & 2.595 & 2.495 & 2.395 & 2.295 & 2.195 \\
Axis 2 & 2.585 & 2.455 & 2.332 & 2.215 & 2.104 & 2.000 \\
\hline
\end{tabular}

the connecting line of $\mathrm{B}_{1}$ and $\mathrm{B}_{5}$. The distances $x_{i}$ of bearings to axes are listed in Table 3 (for Axis 1) and Table 4 (for Axis 2 ). The areas $\Omega$ enclosed by the overturning axis and lateral loading lane are shown in Table 5 for Axis 1 and Axis 2.

Table 5 shows where increasing the bearing eccentricity $e$ made areas $\Omega$ decrease; meanwhile, areas $\Omega_{1}$ of Axis 1 were larger than those $\Omega_{2}$ of Axis 2, which agrees with the theoretical analysis in Section 5.1. The maximum perpendicular distances $d$ from the lateral loading lane to overturning axis were computed as listed in Table 6. The maximum perpendicular distance $d$ decreased with bearing eccentricity $e$, and the distances $d_{1}$ of Axis 1 were less than those $d_{2}$ of Axis 2 , which is also in accordance with the theoretical analysis in Section 5.1.

All the values of $F_{G i}, x_{i}, \Omega$, and $d$ were substituted into (1) to obtain the numerator, $\sum F_{G i} x_{i}$, as plotted in Figure 8. The FSOs $k_{q f}$ were also calculated as plotted in Figure 9.

Figure 8 shows that $\sum F_{G i} x_{1 i}<\sum F_{G i} x_{2 i}$, that is, the numerator of Axis 1, was less than that of Axis 2; this conclusion is again in accordance with the analysis in Section 5.1.

Figure 9 shows where the FSOs of Axis 1 were less than those of Axis 2. In other words, the FSOs increased as bearing



FIGURE 8: Numerators of equation for model bridges with $R=400 \mathrm{~m}$.

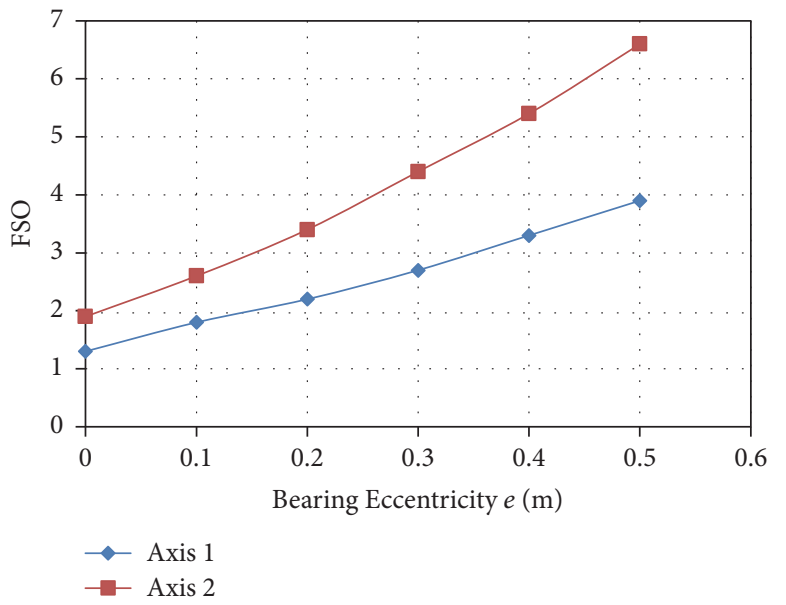

FIGURE 9: Comparison between FSOs of model bridges with $R=$ $400 \mathrm{~m}$.

eccentricity $e$ increased; the inclination of Axis 2 was more than that of Axis 1 in our calculations. According to the axis selection principle, Axis 1 is the target overturning axis (again, in accordance with the theoretical analysis discussed in Section 5.1).

5.2.2. Verification by Models with Curvature Radius of $600 \mathrm{~m}$. For bridges with curvature radius of $600 \mathrm{~m}$, only the models with bearing eccentricities of $0.3-0.5 \mathrm{~m}$ have double overturning axes. If the overturning axis falls along Axis 1, only one axis can be a reasonable overturning axis. The FSOs of models were calculated with curvature radius of $600 \mathrm{~m}$ and bearing eccentricities of $0.3 \mathrm{~m}, 0.4 \mathrm{~m}$, and $0.5 \mathrm{~m}$.

The structural fundamental frequency of models with curvature radius of $600 \mathrm{~m}$ is $4.81 \mathrm{~Hz}$ and their impact factor is 0.2618 . The bearing reactions $F_{G i}$ of models and the distances $x_{i}$ of bearings to overturning axis with eccentricities of $0.3-0.5 \mathrm{~m}$ were computed as plotted in Figure 10 (Axis 1 and Axis 2). Areas $\Omega$ enclosed by the overturning axis and lateral loading lane are listed in Table 7 . It is found that increasing the bearing eccentricity $e$ made areas $\Omega$ decrease; the areas 
TABLE 7: Areas $\Omega$ for model bridges with $R=600 \mathrm{~m}\left(\mathrm{~m}^{2}\right)$.

\begin{tabular}{lccc}
\hline \multirow{2}{*}{ Axis number } & \multicolumn{3}{c}{ Bearing eccentricity $e(\mathrm{~m})$} \\
& 0.3 & 0.4 & 0.5 \\
\hline Axis 1 & 145.8 & 138.3 & 130.8 \\
Axis 2 & 144.2 & 132.9 & 121.6 \\
\hline
\end{tabular}

TABLE 8: The maximum perpendicular distances $d$ for model bridges with $R=600 \mathrm{~m}(\mathrm{~m})$.

\begin{tabular}{lccc}
\hline \multirow{2}{*}{ Axis number } & \multicolumn{3}{c}{ Bearing eccentricity $e(\mathrm{~m})$} \\
& 0.3 & 0.4 & 0.5 \\
\hline Axis 1 & 2.330 & 2.230 & 2.130 \\
Axis 2 & 2.310 & 2.169 & 2.037 \\
\hline
\end{tabular}

of Axis 1 were larger than those of Axis 2, which agrees with the theoretical analysis in Section 5.1. The maximum perpendicular distances $d$ from the lateral loading lane to the overturning axis were computed as listed in Table 8, where the maximum vertical distance $d$ decreases with bearing eccentricity $e$; the distances $d$ of Axis 1 were larger than those of Axis 2, which also supports the analysis in Section 5.1.

After substituting all the values of $F_{G i}, x_{i}, \Omega$, and $d$ in Tables 7 and 8 into (1), the FSOs calculated were plotted in Figure 11. The FSOs changed according to the same rules as those shown in Figure 8. So, for models with curvature radius of $600 \mathrm{~m}$, Axis 1 was again the target overturning axis.

Of all the curved bridges with three equal-span singlecolumn pier structures, in any with two overturning axes, the FSOs of Axis 1 were consistently less than those of Axis 2. In practice, Axis 1 (the connecting line of bearings at central piers) represents the worst-case target overturning axis.

\section{Overturning Axis Selections for Bridges with Two Spans or with Different Bearing Layout}

For curved bridges with two equal spans and single-column piers, there is only one overturning axis to be identified regardless of the curvature radius. When curvature radius is long, the overturning axis is the connecting line of two outmost bearings at the abutments (Figure 12(a)); when curvature radius is short, overturning axis is the connecting line of the central pier with an outmost bearing at the abutment (Figure 12(b)). For curved bridges with two equal spans and double-column piers, the overturning axis is the connecting line of the central pier with an outmost bearing at the abutment (Figure 12(c)).

The overturning axes of curved bridges with three equal spans and single-column piers are shown in Figure 13. When curvature radius is long, the overturning axis is the connecting line of two outmost bearings at the abutments (Figure 13(a)); when curvature radius is short, it is the connecting line of the central pier with an outmost bearing at the abutment (Figure 13(b)). For curved bridges with three equal



FIGURE 10: Numerators of equation for model bridges with $R=$ $600 \mathrm{~m}$.

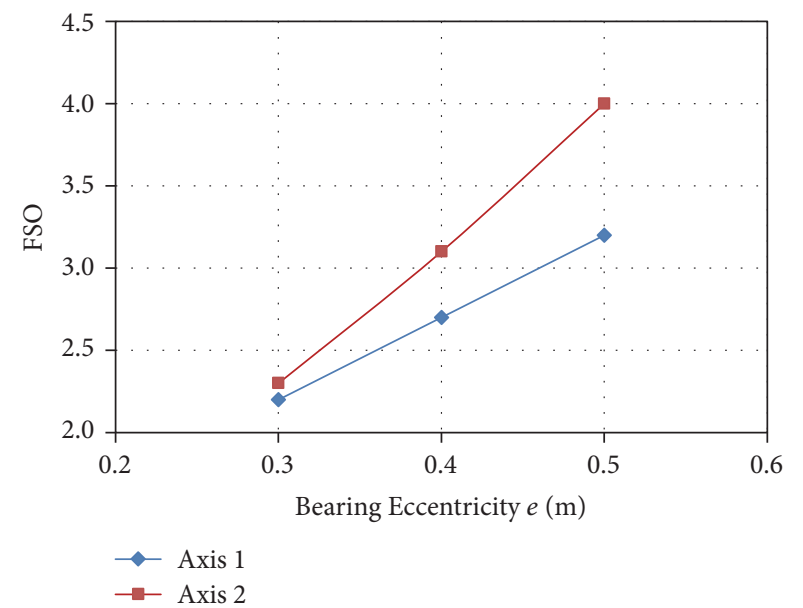

FIGURE 11: Comparison between FSOs of model bridges with $R=$ $600 \mathrm{~m}$.

spans and double-column piers, the overturning axis is the connecting line of the central pier with an outmost bearing at the abutment (Figure 13(c)).

For curved bridges with multispans and single-column or double-column piers, the overturning axis is chosen based on the same principle and is usually the connecting line of the two adjacent outmost bearings.

\section{Conclusions}

In this study, techniques were explored for determining the overturning axes of curved bridges with three equal spans and single-column piers. The influence of curvature radius and bearing eccentricity on the overturning axis was also investigated. Theoretical analysis and model verification together confirmed that Axis 1 is the target overturning axis for models with two possible overturning axes. Our other results can be summarized as follows. 


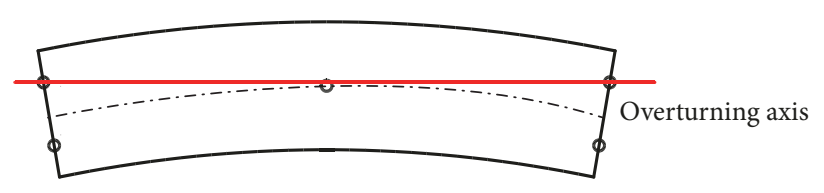

(a) For long curvature radius with single-column pier

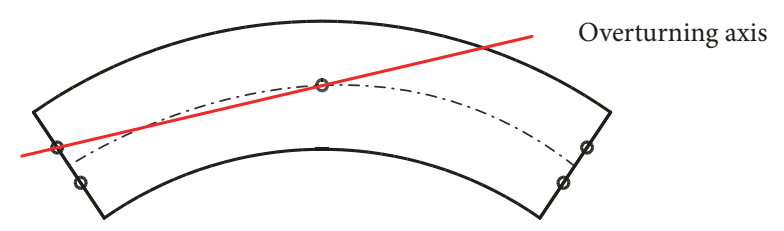

(b) For short curvature radius with single-column pier

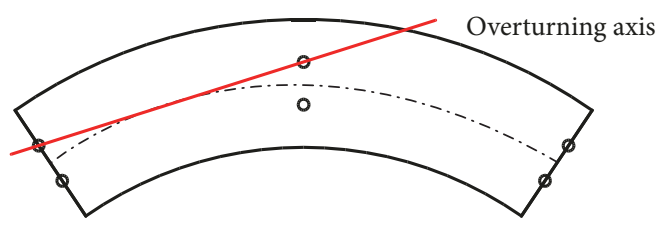

(c) For short curvature radius with double-column piers

FIGURE 12: Overturning axis for curved bridges with two equal spans.

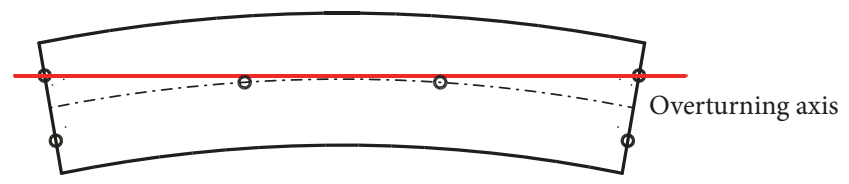

(a) For long curvature radius with single-column piers

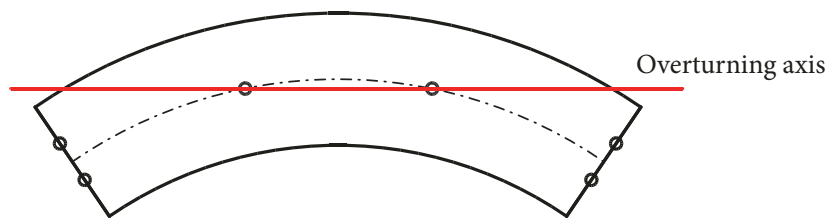

(b) For short curvature radius with single-column piers

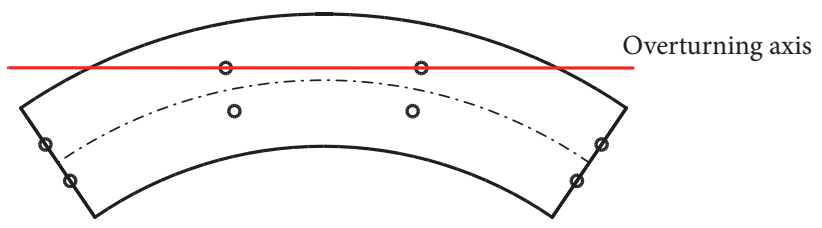

(c) For short curvature radius with double-column piers

FIGURE 13: Overturning axis for curved bridges with three equal spans.

(1) When central piers are in the inner side of the connecting line of outmost bearings at the abutments, the overturning axis is the connecting line itself.

(2) When central piers are in the outmost side of that connecting line, the overturning axis is the connecting line of the two central piers.

(3) When the bearings at central piers are almost in line with the connecting line of outmost bearings at the abutments, bearing eccentricity influences the overturning axis.

(4) For curved bridges with single-column piers influenced by curvature radius and bearing eccentricity, the overturning axis is always the connecting line either of bearings at the central piers or of outmost bearings at the abutments. In other words, no bearings are outside of the overturning axis. All the bearings but the two on the overturning axis are located on the inner side of the axis.

(5) For curved bridges with multispans and single-column or double-column piers, the overturning axis is usually the connecting line of the two adjacent outmost bearings.

\section{Conflicts of Interest}

The authors declare that there are no conflicts of interest regarding the publication of this paper.

\section{Acknowledgments}

This work was supported by the National Natural Science Foundation of China (U1304515).

\section{References}

[1] D. Blower and J. Woodrooffe, Survey of the status of truck safety: Brazil, China, Australia, and the United States, Transportation Research Institute, University of Michigan, Ann Arbo, Michigan, May 2012, Report No. UMTRI-2012-13.

[2] W. Han, J. Wu, C. S. Cai, and S. Chen, "Characteristics and dynamic impact of overloaded extra heavy trucks on typical highway bridges," Journal of Bridge Engineering, vol. 20, no. 2, Article ID 05014011, p. 11, 2015.

[3] J. Zhang, H. Peng, and C. S. Cai, "Field study of overload behavior of an existing reinforced concrete bridge under simulated vehicle loads," Journal of Bridge Engineering, vol. 16, no. 2, pp. 226-237, 2011. 
[4] L. Deng, W. Wang, and Y. Yu, "State-of-the-art review on the causes and mechanisms of bridge collapse," Journal of Performance of Constructed Facilities, vol. 30, no. 2, Article ID 04015005, p. 13, 2016.

[5] E. E. Diaz, F. N. Moreno, and J. Mohammadi, "Investigation of common causes of bridge collapse in Colombia," Practice Periodical on Structural Design and Construction, vol. 14, no. 4, pp. 194-200, 2009.

[6] F. Y. Xu, M. J. Zhang, L. Wang, and J. R. Zhang, "Recent highway bridge collapses in China: review and discussion," Journal of Performance of Constructed Facilities, vol. 30, no. 5, Article ID 04016030, 8 pages, 2016.

[7] W. Xiong, C. S. Cai, B. Kong, and J. Ye, "Overturning-collapse modeling and safety assessment for bridges supported by singlecolumn piers," Journal of Bridge Engineering, vol. 22, no. 11, Article ID 04017084, p. 13, 2017.

[8] Z. Xie and W. Cao, "Analysis of frequent problems on curved bridges," Guangxi Communication Science and Technology, vol. 28, no. 104, pp. 49-51, 2003 (Chinese).

[9] P. Li, J. Zhang, and M. Wang, "Study of method for overturning stability of beam bridge supported by single-column pier," World Bridges, vol. 40, no. 6, pp. 52-56, 2012 (Chinese).

[10] W.-B. Peng, W.-T. Xu, G.-J. Chen, and F.-Y. Lu, "Calculation method for anti-overturning capacity of single column pier girder bridge," China Journal of Highway and Transport, vol. 28, no. 3, pp. 66-72, 2015.

[11] X. Shi, Z. Zhou, and X. Ruan, "Failure analysis of a girder bridge collapse under eccentric heavy vehicles," Journal of Bridge Engineering, vol. 21, no. 12, Article ID 05016009, 10 pages, 2016.

[12] Y. Guo, Q. Chang, and L. Xu, "Analysis on overturning of single pier bridge and reinforcement design method," Applied Mechanics and Materials, vol. 105-107, pp. 1338-1341, 2012.

[13] W. Wang and Q. Wang, "Impact of bearing eccentricity on antioverturning stability performance of ramp bridges," Western China Communication Science and Technology, no. 8, pp. 68-71, 2015.

[14] J. Zhang and W. Xiao, "The Research of single column pier bridge performance against overturning," Highway Engineering, vol. 38, no. 4, pp. 170-173, 2013 (Chinese).

[15] Z. Zhou, X. Ruan, and X. Shi, "Selection of overturning axis in lateral stability calculation of girder bridge," Journal of Chongqing Jiaotong University (Natural Science), vol. 32, no. 5, pp. 907-910, 2013 (Chinese).

[16] W. Peng, H. Zhao, F. Dai, and E. Taciroglu, "Analytical method for overturning limit analysis of single-column pier bridges," Journal of Performance of Constructed Facilities (ASCE), vol. 31, no. 4, Article ID 04017007, p. 16, 2017.

[17] Code for Design of Highway Reinforced Concrete and Prestressed Concrete Bridges and Culverts, Industry standard of China, JTG D62-2004.

[18] Guide Highway Bridges Specifications, American Association of Official: AASHTO, American Association of Official, AASHTO, 2003.

[19] "Steel, Concrete and Composite Bridge, British Standard Institution BS5400: ptl-4:1978".

[20] General Specifications for Design of Highway Bridges and Culverts, Industry standard of China, JTG D60-2015.

[21] W. Peng, F. Dai, and E. Taciroglu, "Research on mechanism of overturning failure for single-column pier bridge," Computing in Civil and Building Engineering, ASCE, pp. 1747-1754, 2014.
[22] A. Jiang and Z. Yang, "Study of overturning axis of curved beam bridge with single-column piers," World Bridges, vol. 41, no. 4, pp. 58-61, 2013 (Chinese).

[23] S. Yuan, G. Dai, and J. Wu, "Discuss the landscape orientation overturn stability of single post wide continued girder bridge," Chinese and Overseas Architecture, vol. 7, pp. 154-157, 2008 (Chinese).

[24] X. Luo, "Research on anti-overturning performance of multispan curved girder bridge with small radius," Acta Mechanica Malaysia, vol. 1, no. 1, pp. 11-15, 2017.

[25] Code for Design of Highway Reinforced Concrete and Prestressed Concrete Bridges and Culverts (the Exposure Draft), Industry standard of China, JTG D62-2012. 


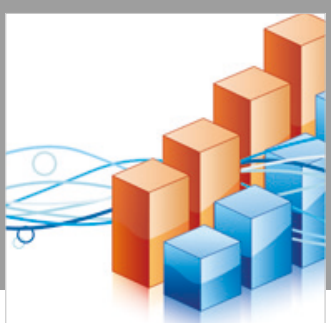

Advances in

Operations Research

\section{-n-m}
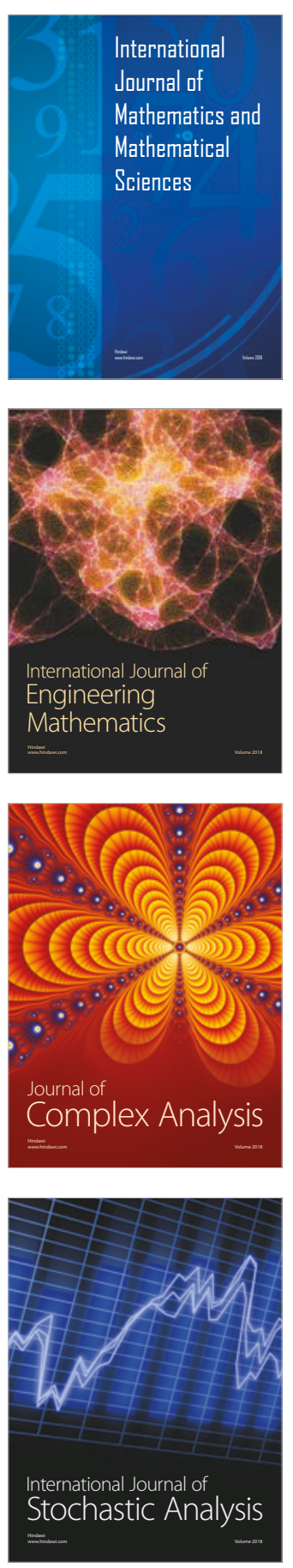
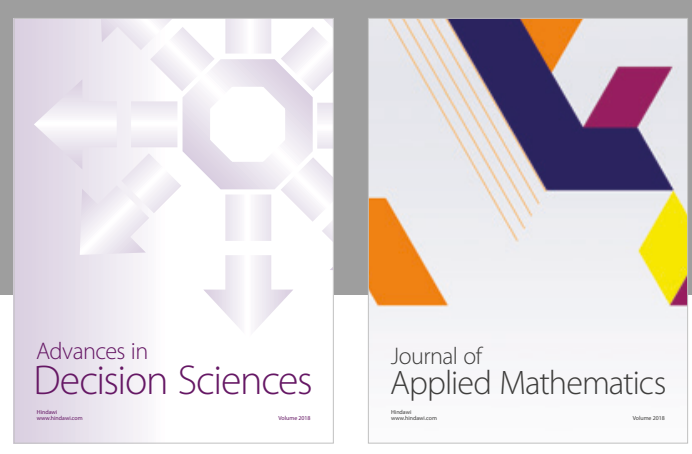

Journal of

Applied Mathematics
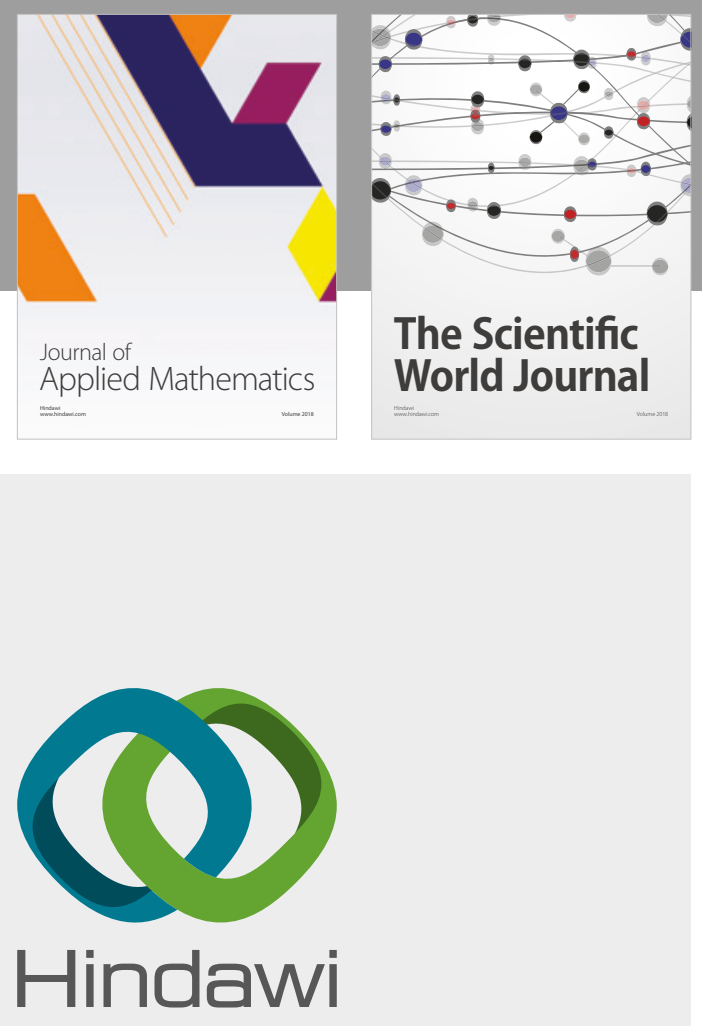

Submit your manuscripts at

www.hindawi.com



Advances in
Numerical Analysis
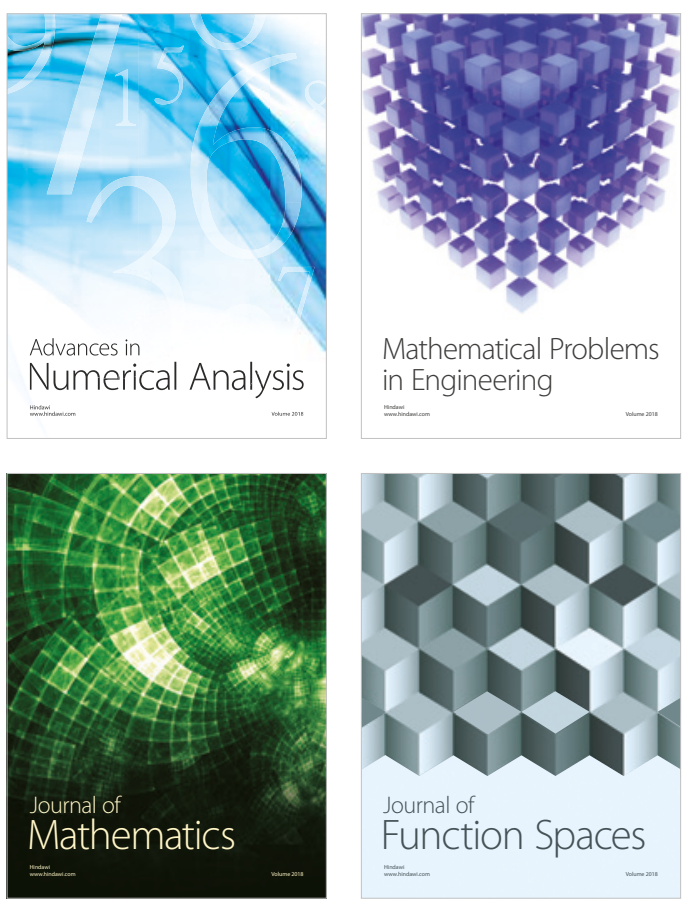

Mathematical Problems in Engineering

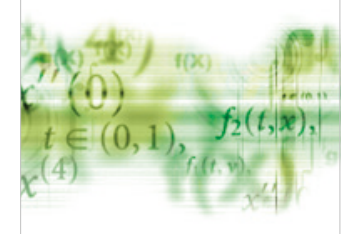

International Journal of

Differential Equations



Journal of

Function Spaces

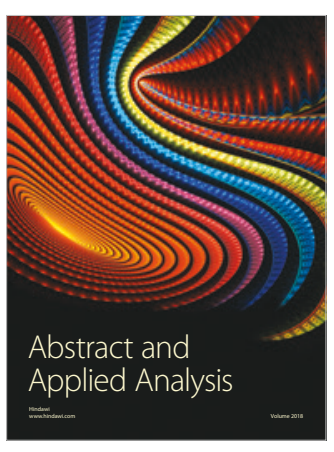

The Scientific

World Journal

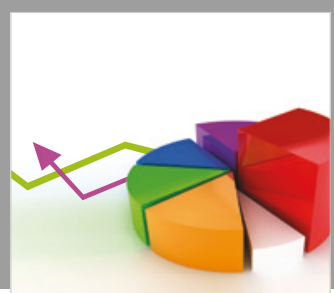

Journal of

Probability and Statistics
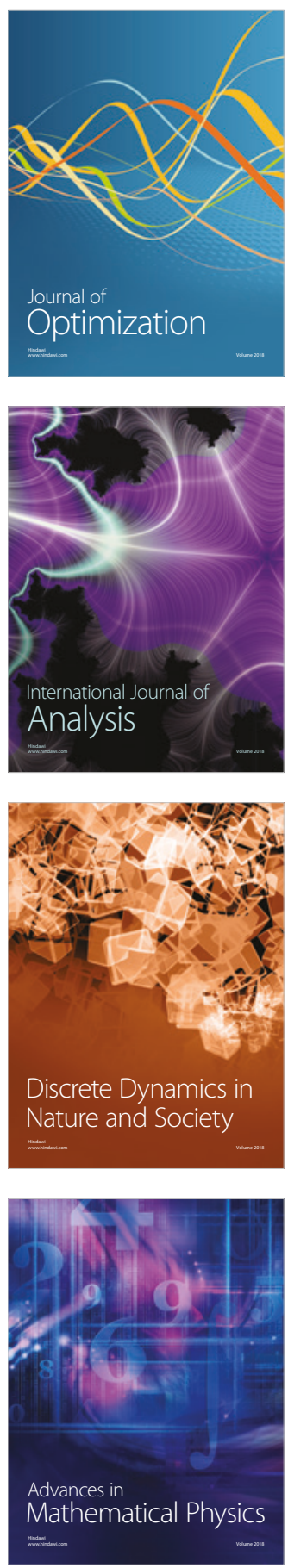